\title{
Degradation of brominated epoxy resin and metal recovery from waste printed circuit boards through batch sub/supercritical water treatments
}

\author{
Mingfei Xing, Fu-Shen Zhang* \\ Research Center for Eco-Environmental Sciences, Chinese Academy of Sciences, 18 Shuangqing Road, Beijing 100085, China
}

\section{H I G H L I G H T S}

- This work provides an efficient and green approach for waste printed circuit boards recycling.

- Debromination of brominated epoxy resins and recycling of metals was simultaneously achieved.

- Brominated epoxy resins can be completely decomposed by sub/SCW treatments.

- Glass fibers and copper foils in WPCBs were liberated and could be easily separated by crushing after sub/SCW treatment.

\section{A R T I C L E I N F O}

\section{Article history:}

Received 29 August 2012

Received in revised form 18 December 2012

Accepted 26 December 2012

Available online 7 January 2013

\section{Keywords:}

E-waste

Waste printed circuit boards

Debromination

Metal recovery

\begin{abstract}
A B S T R A C T
Waste printed circuit boards (WPCBs) contain high amount of brominated flame retardants and heavy metals which may bring a series of environmental and health problems. In the present study, an effective and benign process using sub- and supercritical water (sub/SCW) to simultaneously degrade brominated epoxy resin and recover metals from WPCBs was developed. Experiments were performed in a batch-type reactor with temperatures ranging from 200 to $400{ }^{\circ} \mathrm{C}$, water adding amounts from 10 to $40 \mathrm{ml}$ and holding times from 30 to $240 \mathrm{~min}$. The results showed that brominated epoxy resins (BERs) could be quickly and efficiently decomposed under sub/SCW condition. The debromination rate was $97.8 \%$ by controlling the temperature, water adding amount and holding time at $400{ }^{\circ} \mathrm{C}, 40 \mathrm{ml}$ and $120 \mathrm{~min}$, respectively. Most of the bromine was changed into $\mathrm{HBr}$ and around $97.7 \%$ was enriched in water. Meanwhile, bromine-free oil was obtained of which the main compositions were phenol (58.5\%) and 4-(1-methylethyl)-phenol (21.7\%). After the sub/SCW treatments, the glass fibers and copper foils in the residue can be easily liberated and recovered respectively. The copper recovery rate reached $98.11 \%$ in the purities of $96.74 \%$ (grain size $>2.0 \mathrm{~mm}$ ) and $92.74 \%(0.147-2.0 \mathrm{~mm})$. This study provides an efficient and green approach for WPCBs recycling.
\end{abstract}

(ㄷ) 2013 Elsevier B.V. All rights reserved.

\section{Introduction}

Printed circuit boards (PCBs) is an essential part of electrical and electronic equipments (EEEs). Recently, with the rapid development of electronic manufacturing technologies, the upgrade and replacement of EEEs have been increased rapidly which results in a large quantity of waste printed circuit boards (WPCBs) $[1,2]$. The most commonly WPCBs material is FR-4, which uses glass fibers as the reinforcing materials and brominated epoxy resins (BERs) as a binder [3]. BERs contain a large number of brominated flame retardants (5-15\%, BFRs) for reducing the possibility of fire under the thermal stress [4]. Serious pollution can be generated if PCBs are not properly disposed of since the flame retardants therein may cause the formation of halogenated dioxin-like com-

\footnotetext{
* Corresponding author. Tel./fax: +86 1062849515 .

E-mail address: fszhang@rcees.ac.cn (F.-S. Zhang).
}

pounds, such as polybrominated dibenzo-p-dioxins (PBDDs) or polybrominated dibenzofurans (PBDFs) [5,6]. Meanwhile, WPCBs is attracting more and more attention due to the valuable materials it contains $[7,8]$. Therefore, the recycling of WPCBs has a great practical significance for sustainable development of the human living environment and resources recycling.

In recent years, supercritical water $\left(\mathrm{SCW}, T \geqslant 374{ }^{\circ} \mathrm{C}\right.$, $P \geqslant 22.1 \mathrm{MPa}$ ) is introduced as an environment-friendly method to recycle organic polymers due to its extraordinary properties, such as low viscosities, high mass transport coefficient, high diffusivity and high solubility for organics [9-11]. In our previous works [12], supercritical fluids were employed for debromination and recovery of oil from waste plastic containing brominated flame retardant in computer housing, where the retardant was in additive type [13]. This type of brominated flame retardant could be quickly extracted by supercritical organic fluids. However, it was found that the foregoing process was less effective for extraction 
Table 1

Composition of the WPCBs employed in this study.

\begin{tabular}{|c|c|c|c|c|c|c|c|c|c|}
\hline & \multicolumn{7}{|l|}{ Metal } & \multirow{2}{*}{ Organics } & \multirow{2}{*}{ Glass fiber } \\
\hline & $\mathrm{Cu}$ & $\mathrm{Pb}$ & Sn & $\mathrm{Al}$ & $\mathrm{Zn}$ & $\mathrm{Ag}$ & $\mathrm{Pd}$ & & \\
\hline Wt (\%) & 19.60 & 0.30 & 0.17 & 2.34 & 0.01 & 0.0034 & 0.0016 & 31.25 & 46.32 \\
\hline
\end{tabular}

of brominated flame retardant in WPCBs, since most of the TBBPA in WPCBs mainly used as a reactive type which is covalently bound to the polymer and is difficult to remove the TBBPA by organic solvent unless it was decomposed by thermal decomposition. Water in sub/SCW conditions can act not only as a solvent but also as a reactant, catalyst or product due to the different properties which are mainly dependent on temperature and pressure [14]. Accordingly, in the present work, sub/SCW was tested for extraction and decomposition of TBBPA in WPCBs.

The aims of this study were to: (1) evaluate the feasibility of WPCBs recycling by sub/SCW treatments; (2) examine the debromination efficiency of sub/SCW treatments on WPCBs; (3) identify metal recovery efficiency from WPCBs after sub/SCW treatments; (4) optimize the operation parameters for WPCBs treatments by $\mathrm{sub} / \mathrm{SCW}$.

\section{Materials and methods}

\subsection{Materials}

The WPCBs used in this work were provided by Huaxing Environmental Protection Corporation (China). The WPCBs were mainly disassembled from discarded desktop computers which were made from glass fiber reinforced BERs. The electronic components, such as capacitors, relays were removed first. Then the WPCBs were cut into small pieces $(100 \mathrm{~mm} \times 15 \mathrm{~mm})$ and each piece was about $10 \mathrm{~g}$. After that the WPCBs were dry at $105^{\circ} \mathrm{C}$ for $24 \mathrm{~h}$. The major composition of WPCB were listed in Table 1. Chemical reagents used in the experiments were all analytical reagents unless otherwise mentioned.

\subsection{Apparatus and procedure}

The process comprised of sub/SCW treatments and mechanical treatments. Fig. 1 shows the schematic diagram. The sub/SCW treatments were carried out by using a $100-\mathrm{ml}$ high-pressure reactor made of 316 alloy whose designed temperature and pressure were $500{ }^{\circ} \mathrm{C}$ and $40 \mathrm{MPa}$, respectively. About $10 \mathrm{~g}$ of WPCBs was used in each experiment. Then different amounts of water were added into the reactor which were 10,20 and $40 \mathrm{ml}$. The pressure inside the reactor was monitored by a pressure gauge attached to the reactor. The system pressure was mainly depended on the reaction temperature and the filling amount of water. During the heating process, the system pressure kept on increasing with the increase of temperature. When the system temperature reached the set temperature, the system pressure stopped increasing and stabilized at a certain value. The examined temperatures were $200,250,300,350$ and $400{ }^{\circ} \mathrm{C}$, respectively. Once the reactor reached the set temperature, it was held at the temperature for $30,60,120$ and $240 \mathrm{~min}$, respectively. The reaction conditions of each experiment are described in Table 2. Nos. 5, 6, 7 and 8 in the experiments reached supercritical conditions while others were subcritical. After the treatment, open the insulation cover and the reactor was cooled quickly to room temperature by an electric fan.

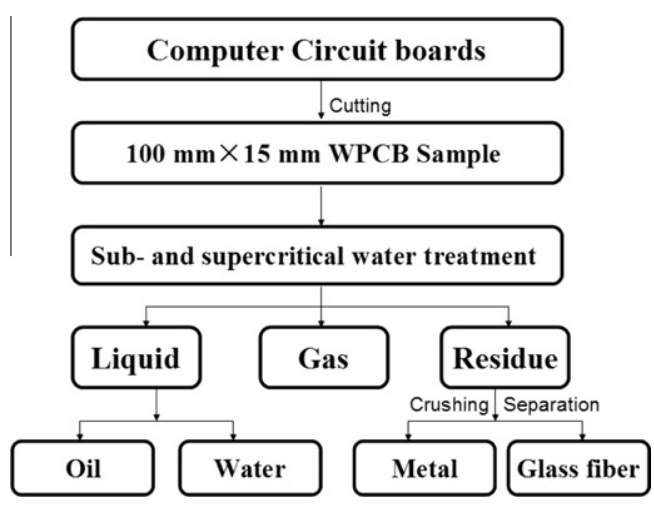

Fig. 1. Schematic diagram of the materials recovery process.

Table 2

Conditions of sub/SCW experiments.

\begin{tabular}{rlllc}
\hline Experiment & $\begin{array}{l}\text { Temperature } \\
\left({ }^{\circ} \mathrm{C}\right)\end{array}$ & $\begin{array}{l}\text { Time } \\
(\mathrm{min})\end{array}$ & $\begin{array}{l}\text { Water adding } \\
\text { amount }(\mathrm{ml})\end{array}$ & $\begin{array}{l}\text { Pressure } \\
(\mathrm{MPa})\end{array}$ \\
\hline 1 & 200 & 120 & 40 & 2.0 \\
2 & 250 & 120 & 40 & 5.0 \\
3 & 300 & 120 & 40 & 10.0 \\
4 & 350 & 120 & 40 & 18.0 \\
5 & 400 & 120 & 40 & 30.0 \\
6 & 400 & 30 & 40 & 30.0 \\
7 & 400 & 60 & 40 & 30.0 \\
8 & 400 & 240 & 40 & 30.0 \\
9 & 400 & 120 & 10 & 4.0 \\
10 & 400 & 120 & 20 & 20.0 \\
11 & 250 & 120 & 10 & 1.5 \\
12 & 250 & 120 & 20 & 4.0 \\
\hline
\end{tabular}

Once the autoclave cooled to room temperature, the reactor was opened and the gaseous phase was passed through methylene dichloride and $\mathrm{NaHCO}_{3}$ solution with the purpose of capturing organic products and inorganic bromine ion, respectively. Then the solid and liquid mixture was removed from the autoclave and filtrated through a pre-weighted filter paper for separation. Afterwards, the inwall of the reactor, pipes and residue on the filter paper were all washed by the solvent and then by deionized water. The final residue with the filter paper were dried to a constant weight to obtain the mass of solid residue, and then sent to comminute in a high-speed universal crusher. At last, standard sieves were used to separate the metals from the nonmetallic materials based on their difference in size and density.

\subsection{Analysis}

The oxygen combustion bomb-ion chromatography (IC, Dionex ICS2000, USA) was applied for the analysis of the bromine content in the solid residue. The bromine content of raw WPCBs was $5.08 \%$. Debromination rate was calculated according to the bromine content before and after the treatment. And the bromine distribution 
was also calculated according to the bromine content in water, oil and residues. The separated metal and nonmetal materials were digested by $\mathrm{HNO}_{3}-\mathrm{HClO}_{4}-\mathrm{HF}$ and examined by inductively coupled plasma optical emission spectrometer (ICP-OES, OPTIMA 2000). The oil was analyzed by a gas chromatograph equipped with mass selective detector (GC/MS, Agilent 7890A/5975C, USA). All the experiments were repeated three times and only the mean values were reported. The measurement errors were around $\pm 1 \%$. The morphological properties of the solid residue were examined by scanning electron microscope with energy disperse X-ray analysis (SEM-EDAX, Hitachi S-3000 N, Japan).

\section{Results and discussion}

\subsection{Effects of various parameters on debromination efficiency}

Fig. 2a shows the effect of temperature on debromination efficiency. It can be seen that the debromination efficiency increased quickly with the increase of temperature. When the temperature was $<200^{\circ} \mathrm{C}$, energy provided by the system was not enough to break chemical bond of BERs resulted in the degradation was restricted to a minimum level and the main products consisted of water and $\mathrm{CO}_{2}$. Debromination rate increased rapidly with the increase of temperature below $350^{\circ} \mathrm{C}$, e.g., increased from $40.7 \%$ at $250{ }^{\circ} \mathrm{C}$ to $93.0 \%$ at $350{ }^{\circ} \mathrm{C}$. When the temperature was $>350^{\circ} \mathrm{C}$, the growth of debromination rate slowed down and reached its maximum value of $97.8 \%$ at $400{ }^{\circ} \mathrm{C}$. The results showed that high temperature could provide enough energy to break chemical bond of BER which was decomposed effectively in SCW condition [15]. It has been reported that temperature was the most important factor on debromination efficiency for two reasons: (1) the dielectric constant decrease with the increase of temperature lead to the hydrogen bonding in water becomes weaker and less persistent: a low dielectric constant causes water to behave more like a organic solvent.
Once the BERs was decomposed into oil and it will be quickly dissolved in SCW to enhance the debromination efficiency [16]; (2) Free radicals reaction was the main polymer decomposition mechanism in supercritical fluids. When the temperature was high enough, the reaction system can provide enough energy to broke the bond of the polymer that cause the formation of free radicals [15].

Water adding amount also plays an important role in the debromination efficiency. The injection volume of water into the reactor is directly related to the reaction pressure. The system pressure increased with the increase of water volume. When the pressure reached the critical point, the nature of the supercritical water changed significantly: the density and viscosity of the supercritical water decreased rapidly while the diffusivity and mass transport co-efficient increased. As a result, BERs can be quickly decomposed into low molecular weight organic compounds and dissolved in the SCW [17]. The change of debromination rate with water adding amount was investigated at $250^{\circ} \mathrm{C}$ and $400^{\circ} \mathrm{C}$ for $120 \mathrm{~min}$ and was shown in Fig. 2b. It indicated that debromination rate kept on increasing with the increase of water adding amount. At $250{ }^{\circ} \mathrm{C}$, the debromination rate increased from $6.45 \%$ at $10 \mathrm{ml}$ to $40.70 \%$ at $40 \mathrm{ml}$. Moreover, the debromination rate under higher temperature $\left(400^{\circ} \mathrm{C}\right)$ was growing much faster than at lower temperature, increased from $31.25 \%$ at $10 \mathrm{ml}$ to $97.82 \%$ at $40 \mathrm{ml}$. Less water was consumed at high reaction temperature compared to low temperature to obtain the same debromination rate. In addition, under high temperature conditions, the pressure increased quickly with the increase of water adding amounts. The pressure was $30 \mathrm{MPa}$ when the temperature and water adding amount were $400{ }^{\circ} \mathrm{C}$ and $40 \mathrm{ml}$. If more water was added into the reactor, the pressure may easily exceed the highest safety pressure (40 MPa) and brought security risks. Therefore, water adding amount was limited at $40 \mathrm{ml}$ in this study.

Fig. 2c shows the effects of holding time on debromination efficiencies. The results indicated that debromination rate increased
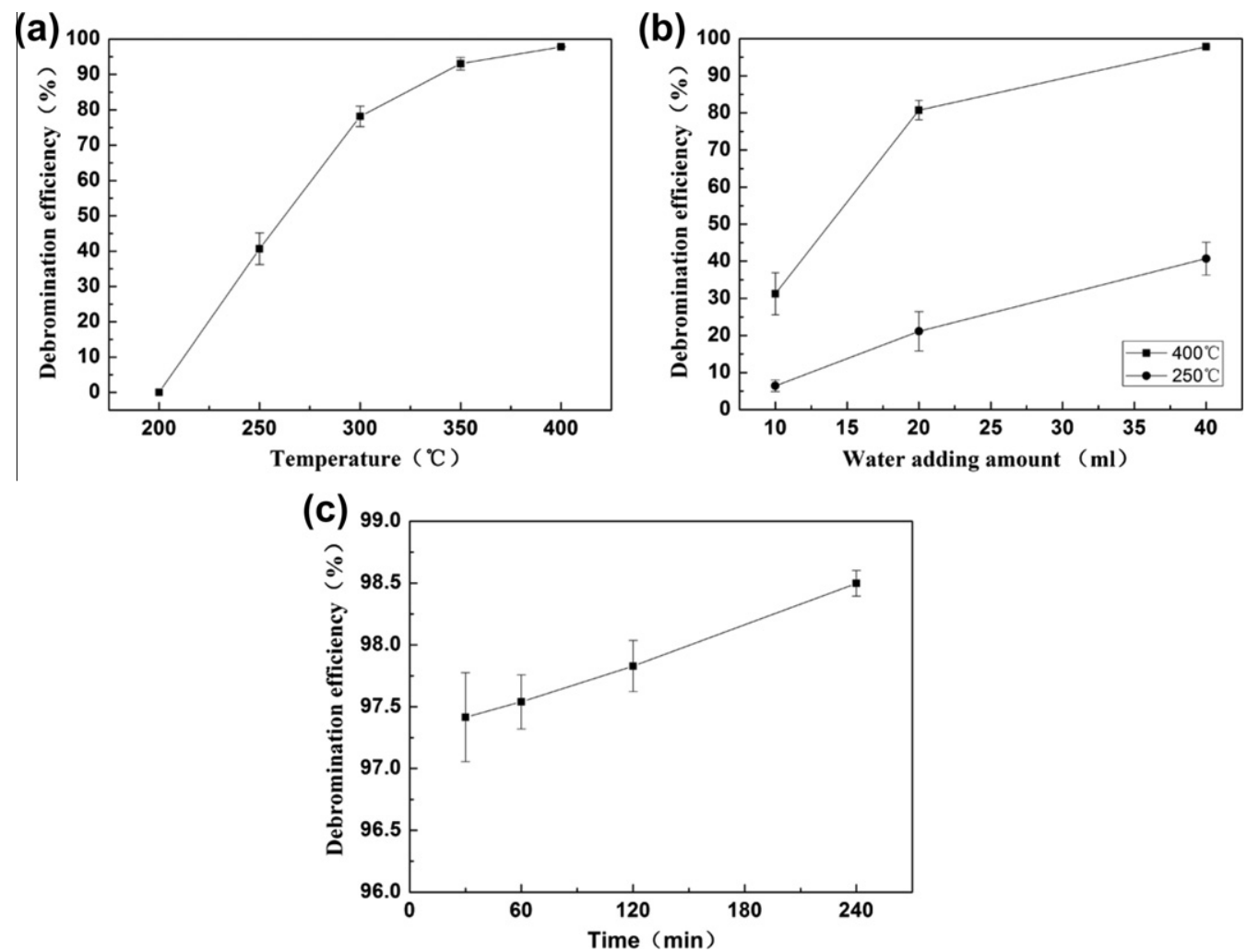

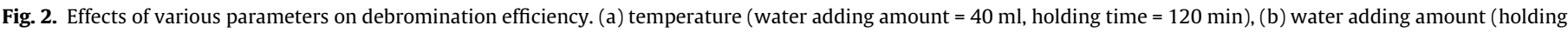
time $=120 \mathrm{~min}$ ) and $(\mathrm{c})$ holding time (temperature $=400^{\circ} \mathrm{C}$, water adding amount $=40 \mathrm{ml}$ ). 
with the increase of residence time. Debromination rate increased rapidly in the first $30 \mathrm{~min}$ (97.49\%) confirming that BERs could be quickly decomposed under SCW condition. When the holding time was more than $30 \mathrm{~min}$, debromination rate increased slowly and reached a maximum at $240 \mathrm{~min}$ (98.5\%). Additional, considering the debromination rate and energy consume, it is recommended that $30 \mathrm{~min}-120 \mathrm{~min}$ is the optimum holding time range with temperature and water adding amount fixed at $400{ }^{\circ} \mathrm{C}$ and $40 \mathrm{ml}$.

\subsection{Analysis of BERs decomposition products}

It has been reported that traditional thermal degradation process of BERs can be divided in three steps: Step one $\left(<297^{\circ} \mathrm{C}\right)$ caused the generation and release of $\mathrm{H}_{2} \mathrm{O}$ and $\mathrm{CO}_{2}$. In step two $\left(297^{\circ} \mathrm{C}\right.$ and $400{ }^{\circ} \mathrm{C}$ ), the BFRs decomposed, releasing $\mathrm{HBr}$ and brominated aromatics. In step three, $\left(>400^{\circ} \mathrm{C}\right)$, the resin decomposed and char was formed [18]. Sub/SCW is an excellent reaction medium for depolymerization or decomposition of polymers. The BERs are relatively easily depolymerized into monomers without catalysts in water which act as reactant as well as solvent [19]. In subcritical region, ion product in water is higher than in ambient conditions, meaning that it acts as an acid/base catalyst precursor. In supercritical region, water assumes particular properties making it highly reactive and miscible with organic molecules and gases due to its low dielectric constant [20]. Therefore, compared with the traditional thermal degradation process, the initial degradation temperature of BERs can be obviously reduced under the sub/SCW reaction conditions. The main decomposition products of BERs were oil which was initially colorless and gradually turned from yellow to brown with the increase of temperature. The oils were further analyzed by GC/MS so as to understand their organic compositions. Table 3 presents the list of the compounds of the oils obtained from $250{ }^{\circ} \mathrm{C}$ to $400{ }^{\circ} \mathrm{C}$. The results showed that the compositions of oil products changed obviously with reaction temperature. At $250{ }^{\circ} \mathrm{C}$, the major compounds of the oil were phenol and 4-(1-methylethyl)-phenol whose relative peak areas were $83.3 \%$ and $7.6 \%$ respectively. However, the liquid products still contained some bromides and mainly in the form of 2-bromo-phenol and its relative peak area was $5.2 \%$. This indicated that BER in WPCBs began to be incompletely decomposed at $250^{\circ} \mathrm{C}$ which was lower than traditional thermal degradation $\left(297^{\circ} \mathrm{C}\right)$. When temperature increased to $300^{\circ} \mathrm{C}$, the relative peak area of phenol decreased to $71.0 \%$ while the 4-(1-methylethyl)-phenol quickly increased from $7.6 \%$ to $21.9 \%$. 2-bromo-phenol was decomposed into $\mathrm{HBr}$ and enriched in the water phase. Under the temperatures of $350{ }^{\circ} \mathrm{C}-400^{\circ} \mathrm{C}$, phenol and 4 -(1-methylethyl)-phenol were still major compounds while the relative peak area of 4-(1-methylethyl)-phenol was around $22.0 \%$, but the phenol decreased to about $57 \%$. Meanwhile, more organic compounds were detected, e.g. 2methyl-phenol, 2-methyl-benzofuran.

\subsection{Bromine distribution}

Fig. 3 shows the bromine distribution among the residue, water and oil after sub/SCW treatments under different temperatures.

Table 3

Main components of the oil identified by GC/MS (relative peak area \%).

\begin{tabular}{llllll}
\hline No. & Compound & $250{ }^{\circ} \mathrm{C}$ & $300{ }^{\circ} \mathrm{C}$ & $350{ }^{\circ} \mathrm{C}$ & $400{ }^{\circ} \mathrm{C}$ \\
\hline 1 & Phenol & 83.3 & 71.0 & 56.4 & 58.5 \\
2 & 4-(1-methylethyl)-phenol & 7.6 & 21.9 & 22.6 & 21.7 \\
3 & 2-bromo-phenol & 5.2 & - & - & - \\
4 & 2-methyl-phenol & - & - & 5.5 & 5.7 \\
5 & 2-methyl-benzofuran & - & - & 4.8 & 5.2 \\
6 & (Z)-9-octadecenamide & 0.8 & 4.7 & 2.7 & 1.9
\end{tabular}

- Not detected.
When each experiment was finished, nitrogen was used to drive the gas away from the reactor and $\mathrm{NaHCO}_{3}$ solution was used to capturing the $\mathrm{HBr}$ in the gas phase. But the results showed that no inorganic bromine was detected in the gaseous phase in all experiments. The reason is that the brominated flame retardants were first degraded into $\mathrm{HBr}$ and enched in gas phase during the sub/SCW treatments process. However, water has high solubility on $\mathrm{HBr}$ and most of the $\mathrm{HBr}$ in the gas phase were transferred into water during the cool process [12]. Therefore, the amount of $\mathrm{HBr}$ in aqueous phase also represented the $\mathrm{HBr}$ content in the gas phase.

Under lower temperature, the bromine in BERs cannot be completely decomposed into $\mathrm{HBr}$ and some bromine still existed in the oil in the formation of organic compounds. Under higher temperature, most of the bromine was transferred into the aqueous in the formation of hydrogen bromide. At $200{ }^{\circ} \mathrm{C}$, the temperature was too low to decompose the BERs and all the bromine were in the residue. When the temperature increased to $250{ }^{\circ} \mathrm{C}$, BERs began to be incompletely decomposed. The degradation product including organic bromine compounds in oil (5.7\%) and inorganic bromine compounds in water (35.0\%). However, about $60 \%$ of the bromine was still left in the residue. By increasing the temperature to $300{ }^{\circ} \mathrm{C}$, bromine in the residue and oil kept on decreasing with the increase of temperature, but bromine in the aqueous phase decreased continuously. Bromine in the solid residue decreased rapidly to $21.8 \%$ while it was only $0.1 \%$ in the oil. With the temperature increased to $350^{\circ} \mathrm{C}$ or higher, most of the bromine was removed from the solid phase and no organic bromine could be found in the oil. In this case, most of the bromine was enriched in the water phase (97.7\%) and only $2.3 \%$ was left in the residue.

\subsection{Recovery of metals and glass fibers}

Copper foil is the main metallic component in WPCBs whose ductility changes little with temperature. Under the action of impact and shearing force, the copper foil was prone to bending instead of being crushed into powders for the high ductility. But the shape of nonmetal was greatly influenced by the temperature. The shapes of nonmetals crushing products varied with different particle sizes which could be observed on SEM as shown in Fig. 4. Fig. 4a shows that the majority of glass fibers were encapsulated in thermosetting resin and the glass fiber could not be separated at $200{ }^{\circ} \mathrm{C}$. At $250{ }^{\circ} \mathrm{C}$, the BER became brittle and all the nonmetal was broken into long single glass fibers. The length of

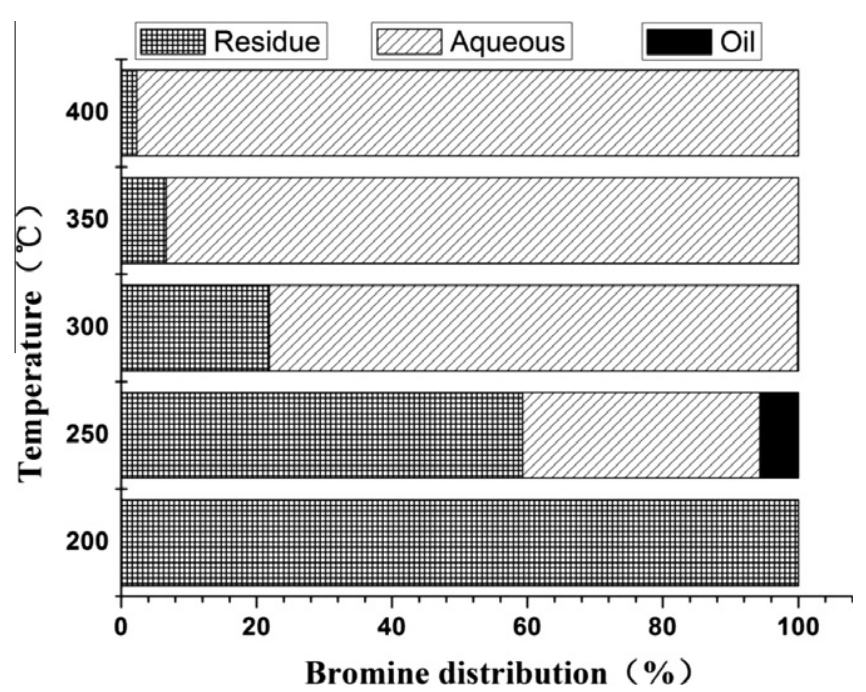

Fig. 3. Relative amount of $\mathrm{Br}$ in different products under various temperatures (holding time $=120 \mathrm{~min}$, water adding amount $=40 \mathrm{ml}$ ) 


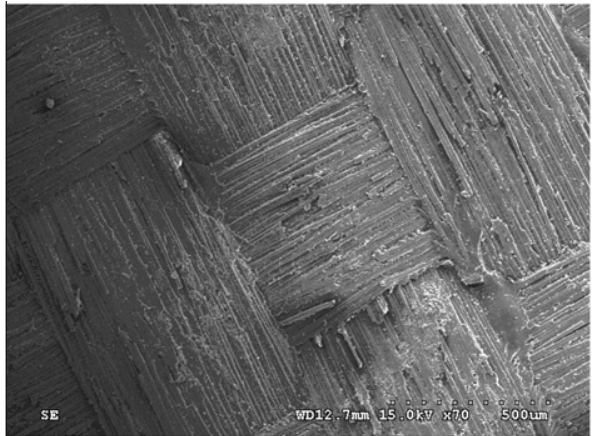

(a)

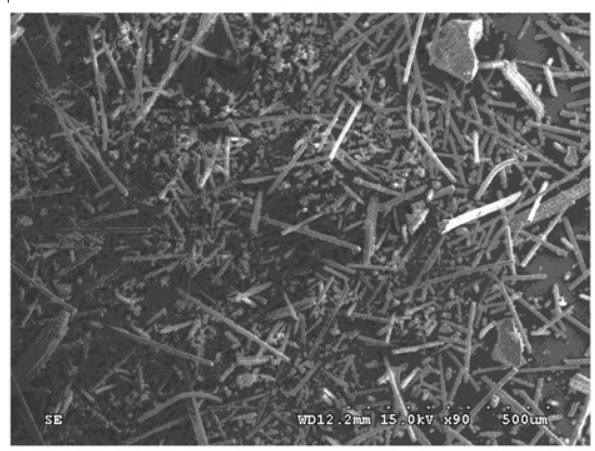

(c)

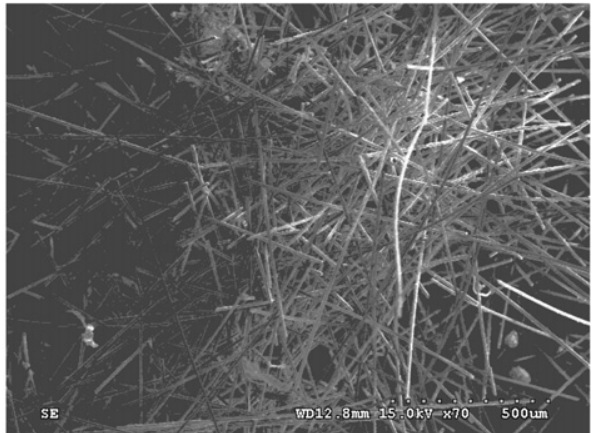

(b)

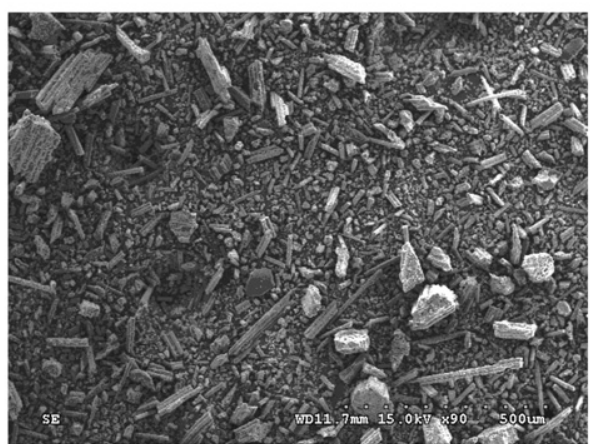

(d)

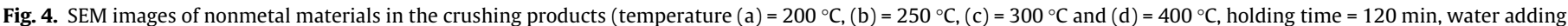
amount $=40 \mathrm{ml}$ )

glass fiber kept on decreasing with the increase of temperature. When the temperature reached $400^{\circ} \mathrm{C}$, the BER was completely decomposed and all the nonmetal could be broken into powders. Under this temperature, the powders nonmetals can be easily separated from the metals by screening separations and the separation pictures of the crushing products are shown in Fig. 5. It could be seen that copper was completely libered by the highspeed universal crusher due to the lower interfacial bonds of the residues after SCW treatments.

10 mesh $(2 \mathrm{~mm})$ and 100 mesh $(0.147 \mathrm{~mm})$ were used for separation in order to study the metal distribution in different particle sizes. Three distinct fractions were observed: large metal products
(LM $>2.0 \mathrm{~mm})$, small metal products $(0.147 \mathrm{~mm}<\mathrm{SM}<2.0 \mathrm{~mm})$ and nonmetal products (NM $<0.147 \mathrm{~mm}$ ). The WPCBs used in this study have four layers of copper foil which can be divided into signaling layer (filamentous and located in the upper and lower surface of WPCBs) and conductive layer (sheet and located in the inner of WPCBs) according to their functions. During the crushing process, the signaling layer mainly concentrated in the SM fraction while the conductive layer mainly concentrated in the LM fraction. Other metals such as $\mathrm{Pb}, \mathrm{Sn}, \mathrm{Zn}, \mathrm{Ag}$ which were used for solders were still left on the surface of signaling layer thus mainly concentrated in SM fractions. Table 4 showed the mass distribution and metal purities within different particle sizes under the optimum

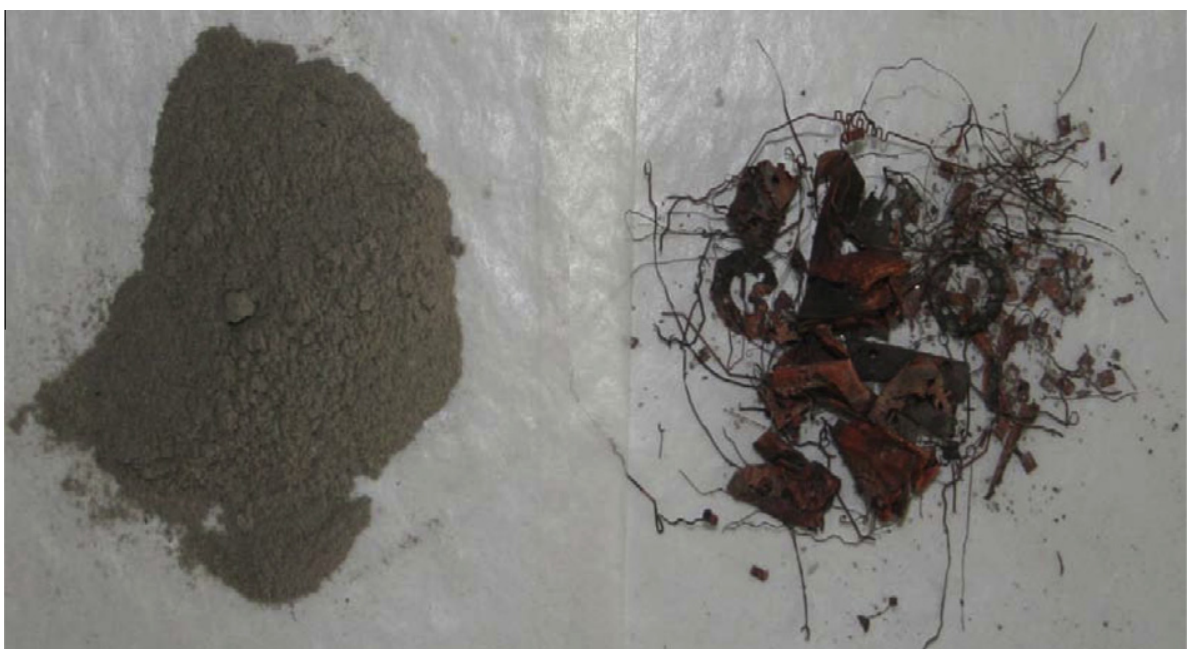

Fig. 5. Pictures of the crushing products (temperature $=400^{\circ} \mathrm{C}, 30 \mathrm{MPa}$, holding time $=120 \mathrm{~min}$, water adding amount $=40 \mathrm{ml}$ ) 
Table 4

Crushing and separating results of solid residue obtained from WPCBs.

\begin{tabular}{|c|c|c|c|c|c|c|c|c|}
\hline & \multirow[t]{2}{*}{ Mass distribution (\%) } & \multicolumn{7}{|c|}{ Metal purity (\%) } \\
\hline & & $\mathrm{Cu}$ & $\mathrm{Pb}$ & Sn & $\mathrm{Al}$ & $\mathrm{Zn}$ & $\mathrm{Ag}$ & $\mathrm{Pd}$ \\
\hline $\mathrm{LM}^{\mathrm{a}}$ & 27.39 & 96.74 & 0.00 & 0.00 & 0.02 & 0.06 & - & 0.004 \\
\hline $\mathrm{SM}^{\mathrm{b}}$ & 8.90 & 92.74 & 2.59 & 1.32 & 0.36 & 0.12 & 0.148 & 0.006 \\
\hline $\mathrm{NM}^{\mathrm{c}}$ & 63.71 & 1.05 & 0.28 & 0.02 & 6.24 & 0.01 & - & 0.004 \\
\hline
\end{tabular}

- No detected.

a Large metal products $<2 \mathrm{~mm}$.

b Small metal products $0.147-2 \mathrm{~mm}$.

c Nonmetal products $<0.147 \mathrm{~mm}$.

condition (temperature, S/L ratio and holding time were $400^{\circ} \mathrm{C}$, $1: 4 \mathrm{~g} / \mathrm{ml}$ and $120 \mathrm{~min}$ ). The mass distribution of LM, SM and NM were $27.39 \%, 8.09 \%$ and $63.71 \%$ respectively. The copper purity of LM and SM were $96.74 \%$ and $92.74 \%$ whereas the copper purity of NM was very low that was only $1.05 \%$. Therefore, high copper recovery rate $(98.11 \%)$ was obtained. $\mathrm{Al}_{2} \mathrm{O}_{3}$ is the main composition of glass fiber, thus $\mathrm{Al}$ was mainly concentrated in NM fraction. However, Pd was found in the three fractions that caused by the special preparation process of copper plated through hole (PTH) $[21,22]$.

\section{Conclusions}

The results of this study demonstrated that sub/SCW treatments were efficient approach for detoxification of brominated flame retardants and simultaneously recovering valuable metals and glass fibers from WPCBs. During the process, BERs can be quickly and efficiently decomposed. Temperature, $S / L$ ratio and holding time were the major parameters controlling debromination efficiency. The optimum temperature, S/L ratio and holding time for the process were $400{ }^{\circ} \mathrm{C}, 1: 4 \mathrm{~g} / \mathrm{ml}$ and $120 \mathrm{~min}$, respectively, and the maximum debromination rate was $97.8 \%$. Most of the bromine changed into $\mathrm{HBr}$ and enrich in water. Meanwhile, bromine-free oil was obtained and the main components were phenol (58.5\%) and 4-(1-methylethyl)-phenol (21.7\%). After sub/ SCW treatments, glass fiber and copper foil in the residue could be easily crushed and separated by a high-speed universal crusher. After screening separation, copper recovery rate reached $98.11 \%$ in the purities of $96.74 \%$ (grain size $>2.0 \mathrm{~mm}$ ) and $92.74 \%(0.147-$ $2.0 \mathrm{~mm}$ ).

\section{Acknowledgments}

The authors are grateful for financial supports from the National Natural Science Foundation of China (21077120 and 51278485), the Environmental Public Welfare Project (201009026).

\section{References}

[1] K. Huang, J. Guo, Z. Xu, Recycling of waste printed circuit boards: a review of current technologies and treatment status in China, J. Hazard. Mater. 164 (2009) 399-408.

[2] J. Cui, E. Forssberg, Mechanical recycling of waste electric and electronic equipment: a review, J. Hazard. Mater. 99 (2003) 243-263.
[3] A.C. Kasper, G.B.T. Berselli, B.D. Freitas, J.A.S. Tenório, A.M. Bernardes, H.M. Veit, Printed wiring boards for mobile phones: characterization and recycling of copper, Waste Manage. 31 (2011) 2536-2545.

[4] Y.-C. Chien, H. Paul Wang, K.-S. Lin, Y.J. Huang, Y.W. Yang, Fate of bromine in pyrolysis of printed circuit board wastes, Chemosphere 40 (2000) 383-387.

[5] R. Weber, B. Kuch, Relevance of BFRs and thermal conditions on the formation pathways of brominated and brominated-chlorinated dibenzodioxins and dibenzofurans, Environ. Int. 29 (2003) 699-710.

[6] H. Duan, J. Li, Y. Liu, N. Yamazaki, W. Jiang, Characterization and inventory of PCDD/Fs and PBDD/Fs emissions from the incineration of waste printed circuit board, Environ. Sci. Technol. 45 (2011) 6322-6328.

[7] Y. Zhou, K. Qiu, A new technology for recycling materials from waste printed circuit boards, J. Hazard. Mater. 175 (2010) 823-828.

[8] H.-L. Chiang, K.-H. Lin, M.-H. Lai, T.-C. Chen, S.-Y. Ma, Pyrolysis characteristics of integrated circuit boards at various particle sizes and temperatures, J. Hazard. Mater. 149 (2007) 151-159.

[9] T. Moriya, H. Enomoto, Characteristics of polyethylene cracking in supercritical water compared to thermal cracking, Polym. Degrad. Stabil. 65 (1999) 373386.

[10] N.-M. Zhu, C.-F. Wang, F.-S. Zhang, An integrated two-stage process for effective dechlorination of polychlorinated biphenyls in subcritical water in the presence of hydrogen donors, Chem. Eng. J. 197 (2012) 135-142.

[11] R. Piñero-Hernanz, C. Dodds, J. Hyde, J. García-Serna, M. Poliakoff, E. Lester, M.J. Cocero, S. Kingman, S. Pickering, K.H. Wong, Chemical recycling of carbon fibre reinforced composites in nearcritical and supercritical water, Composites: Part A 39 (2008) 454-461.

[12] Y. Wang, F.-S. Zhang, Degradation of brominated flame retardant in computer housing plastic by supercritical fluids, J. Hazard. Mater. 205-206 (2012) 156163.

[13] A. Sjödin, H.a. Carlsson, K. Thuresson, S. Sjölin, Å. Bergman, C. Östman, Flame retardants in indoor air at an electronics recycling plant and at other work environments, Environ. Sci. Technol. 35 (2000) 448-454.

[14] L. Qadariyah, Mahfud Sumarno, S. Machmudah, Wahyudiono, M. Sasaki, M Goto, Degradation of glycerol using hydrothermal process, Bioresour. Technol. 102 (2011) 9267-9271.

[15] J. Yin, G. Li, W. He, J. Huang, M. Xu, Hydrothermal decomposition of brominated epoxy resin in waste printed circuit boards, J. Anal. Appl. Pyrol. 92 (2011) 131-136.

[16] Y.-q. Jin, L. Tao, Y. Chi, J.-h. Yan, Conversion of bromine during thermal decomposition of printed circuit boards at high temperature, J. Hazard. Mater. 186 (2011) 707-712.

[17] H.-f. Zhang, X.-l. Su, D.-k. Sun, R. Zhang, J.-c. Bi, Investigation on degradation of polyethylene to oil in a continuous supercritical water reactor, J. Fuel Chem. Technol. 35 (2007) 487-491.

[18] J. Li, H. Duan, K. Yu, L. Liu, S. Wang, Characteristic of low-temperature pyrolysis of printed circuit boards subjected to various atmosphere, Resour. Conserv. Recy. 54 (2010) 810-815.

[19] D. Bröll, C. Kaul, A. Krämer, P. Krammer, T. Richter, M. Jung, H. Vogel, P. Zehner Chemistry in supercritical water, Angew. Chem. Int. Edit. 38 (1999) 29983014.

[20] A. Kruse, E. Dinjus, Hot compressed water as reaction medium and reactant: properties and synthesis reactions, J. Supercrit. Fluid. 39 (2007) 362-380.

[21] A.J. Cobley, D.J. Comeskey, L. Paniwnyk, T.J. Mason, Through hole plating of printed circuit boards using ultrasonically dispersed copper nanoparticles, Circuit World 36 (2010) 9-13.

[22] K. Kordas, J. Bekesi, R. Vajtai, M. Jauhianen, J. Remes, A. Uusimaki, S Leppavuori, T.F. George, L. Nanai, Laser-assisted via hole metallization in PCB materials, J. Electron. Mater. 30 (2001) L21-L24. 